\title{
DRAMATIK KÖYLÜ OYUNLARI ERKEK OYUNLARI
}

(Evlenme töreni bir geçiş ritüelidir. Bugün de halâ bazı yörelerimizde yaşayan bu gelenek gereği, damat bekârlık yaşamına ait olan tüm giysilerini çıkarır, yerine evlilik kurumunun, yeni yaşamın simgesi olan damatlık giysilerini davul, zurna ve türkülerle arkadaşlanının yardımıyla giyer).

KÖYLÜLER

- Getirin Hakko'yu

Giydirin Sakko'yu

Mübarek olsun ağabeyim

Gelinle güveyi.

-

Getirin küleyi

Giydirin köyneği

Mübarek olsun ağabeyim

Gelinle güveyi.

Getirin heleyi

Giydirin yeleği

Mübarek olsun ağabeyim

Gelinle güveyi.

(Halay bittiğinde damat da giyinmiştir).

1. KÖYLÜ - Arkadaşlar, düğünümüze hoşgeldiniz. Tahșin Ağa'nın düğününü şenlendirmek için bir oyun çıkaralım.. Maksat düğün şenlensin...

KÖYLÜLER

- Tamam. Kabul. Oynayalım. Çıkaralım.

2. KÖYLÜ

- Ne oynayalım.

1. KÖYLÜ

KÖYLÜLER

- Değirmenci'yi oynayalım.

1. KÖYLÜ

- Tamam, Değirmenci'yi oynayalım.

- Ama önce kim neyi oynayacak, onu belirleyelim. Hani bizim değirmenci?

(Köylülerden biri öne çıar). 
Tamam, sen değirmenci ol.. Gözlerin fel fecir okuyor, sen Kurnaz Kardeş'i oyna.. Sen de Sefil Kardeş'i.. Tahsin Ağa sen Hakim ol.. Ben Muhtar'1 oynuyorum.. Sizler de değirmen taşı olun. (İki kardeş davul ve zurna eşliğinde AdıyamanGaluç dansı ile buğday ekme ve ekinleri biçmeyi yansilarlar).

KURNAZ KARDEŞ - Ohh.. Ektik, biçtik harmanladık. Buğday ilen samanı ayırdık. He mi kardaşım?

SEFIL KARDEŞ - He ya..

KURNAZ KARDEŞ - Vay benim canım kardeşim. Gel seni bir öpem canım kardeşim.. Ohh.. Ohh.. Şimdi ben diyom ki canım kardeşim, şu buğday ilen samanı aramizda bir pay edelim.

SEFIL KARDEŞ - Edelim.

KURNAZ KARDES - Şimdi ben diyom, diyom, diyom, diyom ki canım kardeşim, bu saman sana, buğday bana.

SEFIL KARDEŞ - Yahu kardeşim, senin bir ineğinle danan var. Samanı onlar yer. Yoksa kışın ölürler. Samanı sen al, buğdayı da ben alayım.

KURNAZ KARDEŞ - Yok canım kardeşim. Ben zaten ineğinen danayı kışın kesecem. Onun için diyom, diyom, diyom, diyom ki, saman sana, buğday bana.

SEFIL KARDEŞ - Yahu kardeşim, senin malın var, davarın var. Ben samanı napıyım? Samanı sen al, buğdayı da ben alayım.

KURNAZ KARDEŞ - Benim sazan kardeşim, benim saman kardeşim, saman sana çok lazım kardeşim. Senin odan var $\mathrm{mi}$ ?

SEFIL KARDEŞ - Var.

KƯRNAZ KARDEŞ - Soban var mı?

SEFIL KARDEŞ - Var.

KURNAZ KARDEŞ - Onun için diyom, diyom, diyom ki benim canım kardeşim, samanı odada kışın yakar kızınırsın. Ben de buğdayı yersem, soğuktan bokum donar, tir tir titrerim gari.

SEFIL KARDEŞ - O zaman ben bunu kabul etmiyorum. Samanı da, buğdayı da pay edelim.

KURNAZ KARDEŞ - Uzatıyon ama kardeşim. Neyinen pay edelim? Ölçümüz yok, terazimiz yok.

SEFIL KARDEŞ - (Kasketini eline alır). Benim bir leğençem var, onunla pay edelim. 
KURNAZ KARDEŞ - (Sinirlenir) İyi kardeşim, ver leğençeni, gel edelim.. sinir ediyon adami... Bir bana, iki, üç bana.. Bir sana, iki-üç, üç, üç sana.

(Kendisi üç ölçü almış, kardeşine iki ölçü vermiştir).

Bir bana, iki, üç bana.. Bir sana, iki-üç, üç, üç sana..

SEFIL KARDEŞ - Yok kardeşim, kabul etmem ben bunu. Seninki fazla oldu, benimki az oldu. Bu sana, bu da bana (Yer değiştirirler).

KURNAZ KARDEŞ - Yok, bu sana, bu bana. Benim canım kardeşim ne fark eder?

(Yer değiştirirler).

SEFIL KARDEŞ - Kabul etmem. Seninki fazla oldu, benimki az oldu.

KURNAZ KARDEŞ - Ne farkeder kardeşim? İkisi de aynı.

SEFIL KARDEŞ - Kabul etmem. O zaman muhtara gidelim. Muhtar..

MUHTAR

- Ne var lan?

KURNAZ KARDEŞ - Muhtar emmi, biz bu saman ilen buğdayı sazan kardeşimle aramızda pay edemedik. Sen bize pay ediver sevabina diyom.

MUHTAR

- İkiniz de bana razı mısınız?

KARDEŞLER

- Hee, razıyık..

MUHTAR

- Sonra nizah falan istemem.. Bir sana, bir sana, bir, iki bana. Bir sana, bir sana, bir, iki bana. Eyvallah bana.

(Muhtar buğdayı alır gider, iki kardeş arkasından bakakalır. Zurna acı bir uzunhava çalmaktadır).

KURNAZ KARDEŞ - Yahu, buğday etsem, unluk kalmıyor, unluk etsem buğdaylık kalmıyor, herkes bana oyun ediyor. Bir değirmenci var. Ben de gidem, ona oyun edem.

(Kurnaz Kardeş boş bir tủluğu şişirir. Köylülerden birkaç kişi türkü söyleyerek yerinden kalkar ve birbirlerinin omuzundan tutarak bir daire oluştururlar ve daireyi sağa doğru döndürürler. Değirmeni yansılamaktadırlar).

DEĞİRMEN

- Değirmen üstü çiçek

Oy kızlar naz eyleme

Orak getirin biçek

Ölürem kızlar naz eyleme. 
KURNAZ KARDEŞ - Selamünaleyküm değirmenci.

DEĞÍRMENCI - Aleykümselam.

KURNAZ KARDEŞ - Şu tuluk dolusu buğdayı sabahınan un yạp. Ben sabahınan gelip alayım.

DEĞİRMENCİ - Şuraya bırak. Ben onu öğütürüm. Sabahınan gelir, onu alır götürürsün.

(Kurnaz Kardeş tuluğu bırakır, gider).

DEĞİRMEN

- Değirmen üstï çiçek

Oy kızlar naz eyleme

Orak getirin biçek

Ölürem kızlar naz eyleme.

KURNAZ KARDEŞ - Selamünaleyküm değirmenci.

DEĞİRMENCI - Aleykümselam.

KURNAZ KARDEŞ - Sabahınan oldu. Gelip unumu, tuluk dolusu buğdayımı alayım, gideyim dedim.

DEĞİRMENCİ : - Senin un uçtu.

KURNAZ KARDEŞ - Yahu nasıl uçar?.. Bir tuluk dolusu. Temiz . yudum, yıkadım. Kardeşim uçar mı yahu?

DEĞIRMENCİ - Senin tuluk boş.

KURNAZ KARDEŞ - Benim tuluk dolu.

DEĞIRMENCI - Senin tuluk boş.

KURNAZ KARDEŞ - Benim tuluk dolu.

DEĞIRMENCI - Senin tuluk boş.

KURNAZ KARDEŞ - Benim tuluk dolu.

(Değirmeni yansılayanlar Kurnaz Kardeş'in üze-

DEĞİRMEN rine yürürler ve onu ortalarına alırlar).

KURNAZ KARDEŞ - Ne yapalım canım, biz de bir mahkemeci var, ona gidip sorariz.

(Değirmenci ve Kurnaz Kardeş Hakim'in yanına giderler).

HAKIM

- Getirin bakayım tuluğu. Bu tuluk doluymuş. Eğilip bükülmemiş de. Bu adamın buğdayını ögütüp teslim edeceksin.

(Değirmenci üzgün tuluğu alır değirmene gider. Değirmen taşları üzgün)...

DEĞİRMEN - Değirmen üstü çiçek

Oy kızlar naz eyleme

Orak getirin biçek

Ölürem kızlar naz eyleme. 
KURNAZ KARDEŞ - Vay benim canım kardeşim. Ne başın önünde durup durun?

SEFIL KARDEŞ - Düşünüyordum da.

KURNAZ KARDEŞ - Öyle düşünmekle olur mu benim sazan kardeşim: Düşün düşün boktur işin. Gel hele gel.. Ben ne ettim biliyon mu?

SEFIL KARDEŞ - Ne ettin?

KURNAZ KARDEŞ - Değirmenci var ya?

SEFIL KARDES - Hee.

KURNAZ KARDEŞ - Tuluğun içine bastım havayı, götürdüm ona kardeşim, kardeşim. Hadi durma kardeşim, akıllı ol, çalıştır saksıyı.

(Sefil Kardeş de tuluğu havayla doldurur).

DEĞİRMEN

- Değirmen üstü çiçek

Oy k1zlar naz eyleme

Orak getirin biçek

Ölürem kızlar naz eyleme.

SEFIL KARDEŞ - - Selamünaleyküm değirmenci.

DEĞİRMENCİ - Aleykümselam.

SEFIL KARDEŞ - Benim tuluk dolusu buğdayımı öğüt, sabahleyin gelip alayım.

DEĞIRMENCİ - Olur. Sen getir bakayım tuluğu şuraya.

SEFIL KARDEŞ - Burası iyiydi.

DEĞIRMENCI - Gel şuraya koy.

SEFIL KARDEŞ - Burası daha iyiydi.

(Değirmeni yansılayanlar Sefil Kardeş'i dairenin içine alırlar, türkü ve dansla dizleriyle vururlar).

DEĞİRMEN

- Değirmen üstü çiçek

Oy kızlar naz eyleme

Orak getirin biçek

Ölürüm' kızlar naz eyleme.

(Sefil Kardeş yediği dayağın acısıyla kardeşine gider).

SEFIL KARDEŞ - Off... Bana yapacağın bu muydu?

KURNAZ KARDEŞ - Ne oldu benim güzel gözlü kardeşim?

SEFIL'KARDEŞ - Değirmenci çok sinirliymiş. Ne derim kaldı, ne gerim yahu.

KURNAZ KARDEŞ - Sinirli değildi esasinda ama.. Ben onunla sabahınan bir demli çay içtiydim, ondan sinir bağlamış olacak herhal. 
SEFIL KARDEŞ - Yahu, o demli çayı ben de içtim, beni de bir sinir bağladı ki...

(Kardeşinin başına vurur ve onu öldürür. Köylüler ölen kardeşin başına toplanırlar ve ağıt yakarlar).

KÖYLÜLER

- İğne yoktur

İplik yoktur

Ipliksiz ölen bu köpek.

Otu yoktur

Suyu yoktur

Susuz ölen bu köpek.

(Ağıt sırasında Kurnaz Kardeş dirilir ve oynamaya başlar. Yüzünde yufkadan yapılmış bir mask vardir).

\section{KARTAL OYUNU}

Topal kartal ağzında bir koyun postuyla sahneye girer, ortada döndükten sonra postu ortaya birakır. Ardından Aptal Kartal girer, ortada dönerken sağdan ve soldan Ana Kartal ile Kurnaz Kartal girip postu almaya çalışırlar. Stilize hareketlerle post kavgası yaparlara. Onlar kavga ederken, Aptal Kartal gelir, postu alır ve gider.

1. KÖYLÜ KÖYLÜLER

1. KÖYLÜ

KÖYLÜLER
- Elinize, kolunuza sağlik.

- Bir oyun daha oynayalım.. Ne oynayalım?.. Çalıçırpı oynayalım..

- Tamam, önce ağacımızı bulalım. Tahsin Ağa deminden beri ortada oturuyor. Tahsin Ağa ağaç olsun.. Sen çoban ol.. Sen köpek. Sizler benim kızlarım olun, siz de koyun olun... Kızlar hazırlanırken gençler de bir Ankara oynasınlar bakalım.

- Tamam, haydi damadi oynatalım.

Güvercin uçuverdi

Kanadin açıverdi

Ben yandtm aman ayrlamam.

El oğlu değil mi aman aman

Sevdi de kaçıverdi.

Oy farfara farfara

Ateş düstü salvara

Ağzım dilim kurudu

Kız yalvara yalvara. 
1. VE 2. KIZ

BABA

1. KIZ

2. $\mathrm{KIZ}$

1. $\mathrm{KIZ}$

2. KIZ

1. VE 2. KIZ

1. $\mathrm{KIZ}$

2. KIZ

1. KIZ

2. KIZ

1. KIZ

2. KIZ

1. KIZ

2. $\mathrm{KIZ}$

1. KIZ

2. KIZ

1. KIZ

2. $\mathrm{KIZ}$

1. $\mathrm{KIZ}$

2. KIZ
Daractk daracık sokaklar

Kizlar misket yuvarlar

Kizlara koca vermiyor

Kocaman kocaman karllar.

(Ağacı yansılayan Tahsin Ağa sahnenin ortasında kollan havada beklemektedir. Çoban kaval çalarak koyunlarnı otlatır. Sonra uykusu gelir, ağacın dibine yatar ve uyur. Kadın giysileri geiymiş iki kişi türkü söyleyerek girer ve sahnenin săğıda bulunan babalarinın yanına otururlar).

- Hululi huli, hululi huli, hululi huli, hululi huli.

- Uuf, hava da bir soğuk ki,.. Kız, siz bulaşık yıkamaktan basska bir bok bilmez misiniz? Soğuktan donuyọk. Gidin de çalı-çırpı toplayın hadi.

- Babam da bizi hep çalı toplamaya gönderiyo, bir gün başımıza bir iş gelecek.

- He valla, gelecek.

- Başım da bir ağrıyo, bir ağrıyo ki.

- Geçmiş olsun. (Türkü söyleyerek çalı-çırpı toplamaya başlarlar).

- Ormanda çalı miytm

Calınin dalı miyım

Tokatlllar dururken

Baskasin alır miyım?

Ormanda çall,.. miyim.

- Kiz Fadime.

- Ne var Zeynep.

- Bak ne buldum.

- Ne buldun?

- Bir çall.

- O ne biçim çalı?

- Bu da çalının dalı.

- Geldim Zeynep.

- Kız bu büyüyor.

- Korktum geri gidiyom.

- Bunun gözü de var.

- K1z hayvan neyim olmasin, isırir misırir.

- Kadife gibi,..

- Mantar cinsi herhal. 
1. $\mathrm{KIZ}$

2. $\mathrm{KIZ}$

1. $\mathrm{KIZ}$

2. KIZ

1. $\mathrm{KIZ}$

2. KIZ

1. $\mathrm{KIZ}$

2. $\mathrm{KIZ}$

1. $\mathrm{KIZ}$

2. KIZ

1. $\mathrm{KIZ}$

2. KIZ

1. $\mathrm{KIZ}$

2. $\mathrm{KIZ}$

1. $\mathrm{KIZ}$

2. $\mathrm{KIZ}$

1. $\mathrm{KIZ}$

1. VE 2. KIZ

KÖYLÜLER
- Katmer, katmer.

- Kız bana birşeyler oluyor.

- Canın çıkmasın. Hadi bir dene.

- Sen büyüksün, önce sen dene.

- Yok önce sen dene.

- Sen etrafa bak.. Ayy..ayy..

- Nasıldı kız?

- Bir de sen dene.

- Etrafa bak kimse olmasin.

- Kimsecikler yok.

- Ayy.. ayy..

- Ne oldu kız?

- Başımın ağrısı neyim kalmadı.

- Her derde deva canım. Aaa, öldü galiba.

- Yok canım, şaşkınlıktan bayıldı.

- Bundan sonra çali toplamaya hep buraya gelelim.

- Olur, hadi gidelim.

- Baba, çalı, çalı.. (Bütün köylüler davul ve zurna eşliğinde, elele tutuşarak seyirciýe dönerler, türkü söylerler ve halay çekerler).

- Yoğurt koydum dolaba ellere vay Bugün bassim kalaba ellere vay

Seni doğuran ana ellere vay

Olsun bana kaynana ellere vay

- Giymiş pembe șalvart

Sallanir saçaklart ellere vay

Yoğurdun üstü kaymak ellere vay

Olur mu yare doymak ellere vay

Yare doydum diyenin ellere vay

Caizdir boynun vurmak ellere vay. 